Bond University

Research Repository

\title{
Hamstring myoelectrical activity during three different kettlebell swing exercises
}

Del Monte, Michael J; Opar, David A; Timmins, Ryan G; Ross, James; Keogh, Justin Wl; Lorenzen, Christian

Published in:

Journal of Strength and Conditioning Research

DOI:

10.1519/JSC.0000000000002254

Licence:

Unspecified

Link to output in Bond University research repository.

Recommended citation(APA):

Del Monte, M. J., Opar, D. A., Timmins, R. G., Ross, J., Keogh, J. W., \& Lorenzen, C. (2020). Hamstring myoelectrical activity during three different kettlebell swing exercises. Journal of Strength and Conditioning Research, 34(7), 1953-1958. https://doi.org/10.1519/JSC.0000000000002254

\section{General rights}

Copyright and moral rights for the publications made accessible in the public portal are retained by the authors and/or other copyright owners and it is a condition of accessing publications that users recognise and abide by the legal requirements associated with these rights.

For more information, or if you believe that this document breaches copyright, please contact the Bond University research repository coordinator. 
Title:

Hamstring myoelectrical activity during three different kettlebell swing exercises.

\section{Running title:}

Hamstring EMG during kettlebell swings

\section{Authors:}

Michael J Del Monte', David A Opar ${ }^{1}$, Ryan G Timmins ${ }^{1}$, James Ross ${ }^{1}$, Justin WL Keogh ${ }^{2,3,4}$, Christian Lorenzen ${ }^{1}$

${ }^{1}$ School of Exercise Science, Australian Catholic University, Melbourne, Australia

${ }^{2}$ Faculty of Health Sciences and Medicine, Bond University, Gold Coast, Australia

${ }^{3}$ Sports Performance Research Centre New Zealand, AUT University, Auckland, New Zealand

${ }^{4}$ Cluster for Health Improvement, Faculty of Science, Health, Education and Engineering, University of the Sunshine Coast

\section{Corresponding Authors:}

\section{James Ross}

School of Exercise Science,

Australian Catholic University,

Victoria, Australia

Postal address: Locked Bag 4115, Fitzroy VIC 3065

Phone Number: +61411570484

Email: james.ross33@yahoo.com

Funding Disclosure: No funding was received for this research 


\section{ABSTRACT}

Kettlebell exercises have become an increasingly popular form of resistance training and component of lower body rehabilitative training programs; despite a lack of scientific literature illustrating internal mechanisms and effectiveness of these approaches. Participants $(n=14)$ performed three different styles of kettlebell swings (hip hinge, squat and double knee extension) and were assessed for medial hamstrings (MH) and biceps femoris (BF) myoelectrical activity via surface electromyography (sEMG). Bipolar pre-gelled $\mathrm{Ag} / \mathrm{AgCl}$ surface electromyography (sEMG) electrodes (10mm diameter, $20 \mathrm{~mm}$ inter-electrode distance) were placed on the participant's dominant limb after correct skin preparation.

There was a main effect for swing type $(\mathrm{p}=0.004)$, where the hip hinge swing elicited a greater overall $\mathrm{MH}$ and BF sEMG in comparison to the squat swing (mean difference $=3.92 ; 95 \% \mathrm{CI}=1.53$ to $6.32 ; \mathrm{p}=0.002$ ) and the double knee extension swing (mean difference $=5.32 ; 95 \% \mathrm{CI}=0.80$ to 9.83; $\mathrm{p}=0.020)$. Across all swing types, normalised percentage of MH sEMG was significantly higher compared to the BF (mean difference $=9.93 ; 95 \% \mathrm{CI}=1.67$ to $18.19 ; \mathrm{p}=0.022$ ). The hip hinge kettlebell swing produced the greatest amount of hamstring sEMG for the three styles of kettlebell swings assessed. These findings have implications for the application of kettlebell swing exercises in strength and conditioning, injury prevention and rehabilitation programs.

Keywords: resistance, rehabilitation,

\section{INTRODUCTION}

Kettlebell exercise has become a popular form of resistance training amongst the general and athletic populations to enhance athleticism, improve general fitness and as a tool for injury rehabilitation (5). The kettlebell swing has been found to provide a stimulus for both improved muscular strength (13, $14,24)$ and endurance $(7,11)$. During training, kettlebells are used for a variety of exercises, but perhaps the most common form of kettlebell exercise is the kettlebell swing. Three of the more prevalent kettlebell swings observed by the authors are the squat swing, hip hinge swing and the 
double knee extension swing. Within Australia, the manner in which the kettlebell swing is taught by coaches may be largely dependent upon the kettlebell exercise prescription certifications the coaches have attended. Whilst these kettlebell swings are explosive total body exercises, which rely to a large extent on the production of lower body forces, their kinematic profiles differ. The squat and hip hinge swings are differentiated by the degrees of ankle, knee and hip ranges of motion (16). They both involve simultaneous flexion and extension of the knees and hips to absorb or propel the kettlebell. As its name suggests, the hip hinge swing is mostly performed with flexion and extension at the hips, and therefore requires the hamstrings to produce force at long muscle lengths to initiate the concentric phase. The hip hinge swing also involves slight knee flexion and extension, with minimal ankle motion, thereby exhibiting. similar lower body kinematics to a Romanian deadlift. The squat swing is performed with increased range of motion of the ankles and knees (16), thus resembling a quarter squat and requiring shorter hamstring muscle lengths than the hip hinge style. The double knee extension swing is common to kettlebell sport and is used during the kettlebell snatch in an effort to promote an efficient trajectory $(25,26)$. In contrast to the other two types of swings, it does not have simultaneous knee and hip extension in both the upwards and downwards phases (16). The first knee extension occurs during the downwards phase, where the knees extend as the hips flex. The second extension takes place during the upwards phase, where the knees and hips extend simultaneously, once the kettlebell passes the knees. This exercise is commonly performed as an assistance exercise for the kettlebell snatch by kettlebell sport athletes in a similar way that weightlifters use the snatch pull as an assistance exercise for the snatch $(9,27)$.

Examining muscle activity during the different variations of the kettlebell swing appears an important step towards understanding the potential role of this exercise in performance training, lower limb injury prevention and rehabilitation. As hamstring strain injury is the most prevalent lower limb injury in running based sport (23) and because there is a noted bias towards injury in the biceps femoris (BF) (20), differences in activity patterns of the medial hamstrings (MH) and BF during typical kettlebell exercise is of interest to practitioners. The kettlebell swing has been proposed to be a useful sport specific exercise due to its large MH myoelectrical activity and its rapid stretch shortening cycle (2). 
Additionally, the one and two armed kettlebell swings were found to produce a sEMG stimulus sufficient to provide a training stimulus for the gluteus maximus, gluteus medius and BF, however data was not collected for $\mathrm{MH}$ (30). Furthermore, it has been suggested that kettlebells can be incorporated into the latter stages of a rehabilitation program and may assist athletes in recovery of lower body injuries (20). Indeed, the swing was found to impose a shear force vector which acts in the opposite direction to traditional exercises, with such kinetic differences being proposed to be useful within lower back rehabilitation and injury prevention programs $(18,30)$. Despite the increased application of kettlebells in training, prevention and rehabilitation programs, there is currently a lack of scientific literature to justify this implementation and exercise selection. Therefore, if one of the aforementioned kettlebell swings displayed greater levels of activity in the BF than the other exercises, this exercise may better strengthen the $\mathrm{BF}$ and provide greater preventative benefits for hamstring strain injury. Additionally, as prior BF strain injury results in long term muscle specific deficits in myoelectrical activity (21), exercises that better target the BF would also be important in rehabilitation.

The hamstrings, particularly the semitendinosus, play an important role in supporting the anterior cruciate ligament (28). Because the semitendinosus has the largest moment arm at the knee of all the hamstrings and contributes to both knee flexion and varus moments, it has been suggested to be the key muscular agonist for reducing the risk of anterior cruciate ligament injury $(19,28)$. As such, recent research has focused on $\mathrm{MH}$ activity in a number of hamstring strengthening exercises, however, only one kettlebell exercise, the hip hinge kettlebell swing, was examined (33). The hip hinge kettlebell swing was performed with $\sim 15^{\circ}$ knee flexion and required the torso to reach a position parallel to the floor, resulting in a peak sEMG $115 \% \pm 55 \%$ and $93 \% \pm 31 \%$ for the $\mathrm{MH}$ and $\mathrm{BF}$, respectively (33). This type of swing was found to have the highest sEMG of MH compared to a number of hamstring exercises, including the Romanian deadlift, Nordic hamstring curl and barbell loaded hip extension (33). Only the BF was measured in the squat swing which was described as being initiated in a squat position with simultaneous hip and knee extension, resulted in a peak sEMG 
of $40 \% \pm 30 \%$ for the $\mathrm{BF}(18)$. With the growing use of kettlebells and their potential use as preventative and rehabilitative exercises for both hamstring strain injury and anterior cruciate ligament injury, determining the myoelectrical activity of the hamstring muscles during the squat, hip hinge and double knee extension kettlebell swings is of interest. Hence the aim of this study was to determine which of the three kettlebell swings (squat, hip hinge and double knee extension) would elicit the greatest hamstring activity. Furthermore we aimed to determine if there was a difference between the $\mathrm{MH}$ and $\mathrm{BF}$ myoeletrical activity during all three swing types.

\section{METHODS}

\section{Experimental Approach to the Problem}

Fourteen trained males performed three different styles of kettlebell swings (hip hinge, squat and double knee extension). The myoelectrical activity of $\mathrm{MH}$ and $\mathrm{BF}$ was assessed within the three different styles of swings via bipolar pre-gelled $\mathrm{Ag} / \mathrm{AgCl}$ sEMG. Uniaxial inline mechanical goniometers were used to record hip and knee joint angles and determine sEMG within the eccentric and concentric phases. The sEMG within the different styles and muscle actions was analyzed using a $2 \times 3$ repeated measures general linear model.

\section{Participants}

Fourteen physically active males $(30.1 \pm 3.9$ years; $1.81 \pm 0.20 \mathrm{~m} ; 89.89 \pm 19.72 \mathrm{~kg})$ with a minimum of six months continuous kettlebell training experience were recruited to participate in this study. Participant skill level amongst swing type was varied, if a participant was unfamiliar with any style, additional coaching was given. The number of additional coaching sessions were based on the individual ability to perform the exercise at a proficient level. All participants were currently in a healthy state, defined by having no significant injury which could impact on the performance of kettlebell exercise. Prior to commencement of the study, all participants gave informed consent and 
were made aware that they could freely withdraw at any time. Ethical approval was gained from the Australian Catholic University Human Research Ethics Committee.

\section{Procedures}

Bipolar pre-gelled $\mathrm{Ag} / \mathrm{AgCl}$ surface electromyography (sEMG) electrodes (10 mm diameter, $20 \mathrm{~mm}$ inter-electrode distance) were placed on the dominant limb (preferred kicking limb) of the participant after correct skin preparation (21). Electrodes were placed half way between the ischial tuberosity and the $\mathrm{MH}$ and $\mathrm{BF}$ epicondyles of the tibia. These sites were identified by palpation and muscle locality was confirmed during an isometric knee flexion test. It is not possible to distinguish between semitendinous or semimembranosus when analysing sEMG from the medial aspect of the posterior thigh. Therefore all sEMG sampled from this site was classified as the MH. The reference electrode was placed on the ipsilateral medial tibial condyle. All skin preparation and electrode placement was conducted in accordance with the Surface Electromyography for the Non-Invasive Assessment of Muscles (SENIAM) guidelines (10). Correct electrode positioning was confirmed by visual observation of sEMG signal activity during resisted internal and external rotation of the knee. All

participants performed this test in a prone position with their respective knee flexed to $90^{\circ}$ degrees to

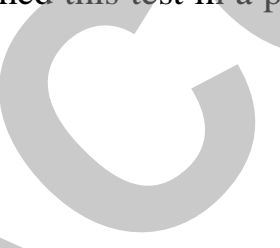

detect any cross-talk $(22,29)$. After correct electrode positioning was confirmed, two five-second maximum voluntary isometric contractions (MVIC) of knee flexion were performed against manual resistance to elicit a maximum EMG signal. These were performed with the participant lying in a prone position with their knee fully extended. This MVIC EMG signal was used for normalisation of EMG signal during the subsequent kettlebell swings. 
Hip and knee joint angles throughout each swing were recorded using uniaxial inline mechanical goniometers (Noraxon USA Inc., Scottsdale, USA). The hip goniometer was placed over the axis of rotation (greater trochanter of femur) and the two moveable arms aligned with the midline of the torso and the lateral femoral epicondyle, respectively (4). The knee goniometer was placed over the axis of rotation in line with the femoral epicondyle and the two moveable arms aligned with the greater trochanter of the femur and the lateral malleolus of the fibula (4). Tests of hip and knee joint angles were performed to ensure the correct positioning of goniometers by comparing computed angles with direct manual measures of various hip and knee joint positions.

A standardised five minute kettlebell specific warm up using submaximal loads was administered prior to work sets. For the work sets, the selected mass of the kettlebell was the maximum mass the participant could swing for a cadence of 35-40 repetitions/min during the participant's typical training sessions and ranged from $16-48 \mathrm{~kg}$. One set of ten repetitions was completed per swing with the order of swing type randomized across the participant pool, across the same testing session. Each set of a swing time was separated by three minutes rest to minimize the effects of performance fatigue. The three swing types were all initiated with the participant standing, holding the kettlebell with both hands, gently pulling the kettlebell forward before swinging the kettlebell backwards between the legs (5). The squat swing was initiated with significant hip and knee flexion, whilst the hip hinge swing was performed from a relatively stiff legged position, allowing for around 10-15 degrees of knee flexion (33). The double knee extension swing was initiated with knees extended following a dipping action, slightly flexing at the knees as the kettlebell was propelled forwards. All three kettlebell swings required explosive extension of the knees and/or hips to generate sufficient force to swing the kettlebell to a peak height at sternum level (33). After reaching peak at or close to sternum level, the kettlebell then retraced its trajectory backwards between the legs and the movement was repeated. 
Surface EMG and goniometer data was sampled simultaneously at $1000 \mathrm{~Hz}$ through a 4-channel signal acquisition unit (Myotrace 400, Noraxon USA Inc., Scottsdale) $($ amplification $=1000$, common mode rejection ratio $=>100 \mathrm{~dB}$ ) and stored for later analysis using LabChart 5 (ADInstruments, New South Wales, Australia). Following data collection, raw sEMG signals were band-pass Bessell filtered between $20-500 \mathrm{~Hz}(24 \mathrm{~dB}$ roll off) and then full wave rectified using the root-mean-square method across a 200ms window. sEMG, for MH and BF respectively, were normalised to the average sEMG amplitude of the middle three seconds during the five-second isometric knee flexion MVIC. The magnitude of mean sEMG was determined for each swing type using the middle six repetitions of each set and expressed as a percentage of sEMG during the isometric knee flexion MVIC. The magnitude of mean sEMG was also determined during eccentric and concentric phases of the middle six repetitions of each swing, using the gradient of hip joint position trace to define each phase.

\section{Statistical Analysis}

Shapiro-Wilk test was employed to ensure the normality of all data and Mauchly's test was used to determine sphericity. A 2x3 repeated measures general linear model (hamstring muscle sEMG activity $[\mathrm{BF}, \mathrm{MH}]$ ) by swing type (squat, hip hinge, double knee extension) was employed with post hoc pairwise comparison used if an effect was detected, with Bonferonni corrections used to account for multiple comparisons. Additionally, there was no statistical effect on testing order ( $\mathrm{p}$ range $=0.579$ to 0.936). Data analysis was conducted in SPSS (version 22.0; SPSS Inc., Chicago, IL, USA) with statistical significance set at $\mathrm{p} \leq 0.05$.

\section{RESULTS}

Post-hoc power analysis was completed using G-Power (input parameters: effect size $=0.8$, alpha $=0.05$, sample size $=14)(8)$ and indicated a power of 0.79 when detecting a large effect of paired data (6). There was a main effect for both swing type $(\mathrm{p}=0.004)$ and normalised hamstring muscle sEMG percentage $(\mathrm{p}=0.022)$, however the interaction effect was not significant $(\mathrm{p}=0.412)$. Post hoc testing revealed that the hip hinge swing elicited significantly greater hamstring sEMG activity compared to the squat swing (mean difference $=3.92 ; 95 \% \mathrm{CI}=1.53$ to $6.32 ; \mathrm{p}=0.002 ;$ Table 1 ) and 
double knee extension swing (mean difference $=5.32 ; 95 \% \mathrm{CI}=0.80$ to $9.83 ; \mathrm{p}=0.020$; Table 1 ). There was no difference between the hamstring sEMG activity of the squat swing compared to the double knee extension swing (mean difference $=1.39 ; 95 \% \mathrm{CI}=-3.46$ to $6.24 ; \mathrm{p}=1.000$ ). With respect to the main effect for hamstring muscle sEMG activity, the MH displayed significantly greater activity across all swing types compared to the $\mathrm{BF}$ (mean difference $=9.93 ; 95 \% \mathrm{CI}=1.67$ to $18.19 ; \mathrm{p}$ $=0.022)$.

Table 1. about here

During the concentric phase of the movement there was a main effect for both swing type $(p=0.049)$ and hamstring muscle $\mathrm{sEMG}(\mathrm{p}=0.046)$ but the interaction effect was not significant $(\mathrm{p}=0.255)$. Post hoc testing revealed that the MH sEMG activity was significantly greater compared to the BF across all swing types (mean difference $=11.54 ; 95 \% \mathrm{CI}=0.22$ to $22.86 ; \mathrm{p}=0.046$; Table 1 ). There were, however, no significant differences in hamstring sEMG activity across the three swing types (squat vs hip hinge, mean difference $=-5.37 ; 95 \% \mathrm{CI}=-11.88$ to $1.13 ; \mathrm{p}=0.123$; squat vs double knee extension, mean difference $=3.40 ; 95 \% \mathrm{CI}=-6.28$ to $13.09 ; \mathrm{p}=1.000$; hip hinge vs double knee extension, mean difference $=8.78 ; 95 \% \mathrm{CI}=-2.41$ to $19.97 ; \mathrm{p}=0.152$ ).

Table 2. about here

For the eccentric phase of the movement there was a main effect detected for both swing type $(\mathrm{p}=0.014)$ and hamstring muscle $\mathrm{sEMG}(\mathrm{p}=0.007)$, however the interaction effect did not reach significance $(\mathrm{p}=0.120)$. Post hoc testing revealed that the MH sEMG activity across all three swings was significantly greater than the activity of $\mathrm{BF}$ (mean difference $=6.61 ; 95 \% \mathrm{CI}=2.19$ to $11.04 ; \mathrm{p}=$ 0.007; Table 1). There was, however, no significant differences between individual swings with respect to sEMG activity of the hamstrings (squat vs hip hinge, mean difference $=-4.94 ; 95 \% \mathrm{CI}=-$ 10.18 to $0.30 ; \mathrm{p}=0.067 ;$ squat vs double knee extension, mean difference $=2.33 ; 95 \% \mathrm{CI}=-3.29$ to 
7.94; $\mathrm{p}=0.826$; hip hinge vs double knee extension, mean difference $=7.27 ; 95 \% \mathrm{CI}=-0.814$ to $15.36 ; \mathrm{p}=0.084)$.

\section{DISCUSSION}

The main objective of the current study was to determine the myoelectrical activity of the MH and the BF during three different kettlebell swing styles. The major finding was that during all contraction modes and swings, the $\mathrm{MH}$ had a significantly greater myoelectrical activity than the BF. Additionally, the hip hinge displayed a significantly greater level of combined myoelectrical activity during the entire repetition when compared to both the squat swing and double knee extension. This may enable the practitioner to select a kettlebell swing variation that may be most appropriate for their clients' needs.

To the authors knowledge this is the first study, which compared the hamstring myoelectrical activity of three different kettlebell swings. Previously, the hip hinge style swing with a $32 \mathrm{~kg}$ kettlebell was found to have greater peak and mean power compared to the barbell back squats with $80 \%$ of 1RM. In contrast, the kettlebell swing produced significantly less mean and peak force compared to the back squat(14). A six week intervention that involved weightlifting and traditional heavy resistance produced a significantly greater increase in back squat performance than a program of kettlebell swings and squats with a $16 \mathrm{~kg}$ kettlebell (24). Despite smaller improvement in maximal strength, kettlebell training resulted in a similar improvement in vertical jump performance (24). Thus, within a sequenced periodized performance program, the kettlebell swing may be a useful tool within a power phase. Further, the hip hinge kettlebell swings' stretch shortening cycle, horizontal propulsion and MH myoelectrical activity may offer a sports specific stimulus for sprinting based athletes (2). As such, the hip hinge swing may be the best suited swing for developing hamstring power or for return to play within end stage hamstring rehabilitation. 
Two different studies, with one adopting the squat swing and the other hip hinge style swing, resulted in similar levels of myoelectrical activity for the gluteus maximus and medius. The percentage MVIC for the gluteus maximus and medius was $76.1 \% \pm 32.1 \%$ and $70.1 \% \pm 23.6 \%$ for the squat swing, whilst the hip hinge swing MVIC was $75.0 \% \pm 55.4 \%$ and $55.5 \% \pm 26.3 \%$, which suggests that both styles may be useful for gluteal training $(18,30)$. In comparison, the double knee extension requires a fairly unique technique, which has no real resemblance to other commonly used exercises and may be more complex to teach than other kettlebell swings. From a kettlebell sport perspective, as the double knee extension had the lowest hamstring muscle activation across all variables, the swing may be the preferred choice to use where endurance is required, such as during a kettlebell snatch discipline in competition, where a maximum number of snatches are performed within ten minutes (26). In contrast, the kettle bell swing may be better suited as a power training stimulus compared to the kettlebell snatch. The hip hinge swing performed with maximal explosive intention was found to have a greater horizontal GRF compared to the kettlebell snatch, with no significant different within vertical GRF and BF myoelectrical activity $(12,18)$. Further, the hip hinge swing with a $12 \mathrm{~kg}$ or 16 $\mathrm{kg}$ kettlebell was found to have a peak MVIC $115 \% \pm 55 \%, 93 \% \pm 31 \%$ for the MH and BF, which was greater compared to a 12 RM Romanian deadlift (33). Romanian deadlifts have been found to be an effective hamstring exercise as they have been shown to produce greater hamstring myoelectical activity compared to lying curls and good mornings (17). Thus, progressing from a Romanian deadlift the hip hinge kettlebell swing may offer strength and conditioning coaches an additional method to overload the hamstring musculature. Further study into the three different kettlebell swing types should investigate EMG of other prime movers such as the gluteus maximus and quadriceps to be able to make more informed decisions about the most efficient exercise selection.

The observation that $\mathrm{MH}$ myoelectrical activity was higher than in the BF during all three kettlebell swing variations may have implications for ACL and hamstring injury prevention and rehabilitation programs and performance. The MH play an important role in 'unloading' the ACL during anterior 
tibial translation (19) and help to control valgus motion of the knee (15). Therefore, the inclusion of MH dominant exercises (e.g. kettlebell swing training) may be considered beneficial within ACL injury prevention programs aimed at reducing the extent of anterior tibial translation and limiting the extent of valgus collapse. The finding that the hip hinge swing, when compared to the other two swing types, displayed a significantly higher level of combined myoelectrical activity may also have important consequences for hamstring strain injury rehabilitation practices and performance. The squat swing resembles a motor pattern in commonly used exercises such as a weighted squat or squat jump. The squat swing can be progressed to the hip hinge swing to increase demands upon the hamstrings. Alternatively, once the athlete is able to perform the Romanian deadlift, they could be progressed to the hip hinge kettlebell swing. This progression from the Romanian deadlift to the hip hinge kettlebell swing may increase specificity with the introduction of a stretch shortening cycle, a larger horizontal propulsion component and greater movement velocity (2).

There are limitations in the current study. Each participant had an inherent preference towards one of the three swing styles. However all participants were considered proficient and had performed the three swing styles on multiple occasions in the six months preceding testing. Additionally, the current study only consisted of male participants. These findings may have limited implications to rehabilitative and prevention programs as this wasn't the focus of this study. Finally, it must be acknowledged that there are limitations inherent with the use of sEMG. The level of myoelectrical activity assessed in this study can be influenced by factors related to the extent of muscle activation (e.g. motor unit recruitment and firing rates) as well as the level of motor unit synchrony (32). Despite this, the lower level of activity during the eccentric phase in comparison to the concentric phase is similar to studies which have utilised superimposed nerve $(1,3,31)$. Therefore, the measures in this study are considered to be representative of muscle activation.

In conclusion, this study found that during three different kettlebell swing types, $\mathrm{MH}$ myoelectrical activity was greater than the BF during all contraction modes and across the entire repetition. 
Additionally, the combined hamstring myoelectrical activity was significantly greater during the hip hinge kettlebell swing when compared to the squat and double knee extension swings. The results obtained in this study may be of use to practitioners who choose to incorporate kettlebells into a performance, hamstring and ACL rehabilitative and preventative training programs.

\section{Practical Applications}

This study demonstrated significantly higher $\mathrm{MH}$ than BF myoelectrical activity during the three observed kettlebell swings. These results support the incorporation of these movements into various performance, rehabilitative and injury prevention programs. Greater hamstring strength has been highlighted as an important mechanism in knee injury prevention (33), with the one of the $\mathrm{MH}$ muscles (semitendinosus) specifically serving a supporting role to the ACL (28). Further, the greater myoelectrical activity within the MH compared to the BF may be specific to sprinting (2). Thus the hip hinge kettlebell swing may be a useful addition to a performance or injury prevention ACL program, as this style of swing has demonstrated greater $\mathrm{MH}$ myoelectrical activity compared to the other two swings. Additionally, the squat swing or double knee bend swing may be progressed to the hip hinge swing to increase the demands placed upon the hamstrings. Further investigation of the effectiveness of kettlebell swings and its role in performance, injury prevention and rehabilitative programs is still needed.

\section{Acknowledgements}

The authors received no financial support for this project.

\section{Conflict of interest}

The authors report no conflicts of interest. 


\section{REFERENCES}

1. Amiridis I, Martin A, Morlon B, Martin L, Cometti G, Pousson M, and Van Hoecke J. Coactivation and tension-regulating phenomena during isokinetic knee extension in sedentary and highly skilled humans. European journal of applied physiology and occupational physiology 73: 149-156, 1996.

2. Beardsley $\mathrm{C}$ and Contreras B. The Role of Kettlebells in Strength and Conditioning: A Review of the Literature. Strength \& Conditioning Journal 36: 64-70 2014.

3. Beltman J, Sargeant A, Van Mechelen W, and De Haan A. Voluntary activation level and muscle fiber recruitment of human quadriceps during lengthening contractions. Journal of Applied Physiology 97: 619-626, 2004.

4. Boyd BS, Wanek L, Gray AT, and Topp KS. Mechanosensitivity of the lower extremity nervous system during straight-leg raise neurodynamic testing in healthy individuals. journal of orthopaedic \& sports physical therapy 39: 780-790, 2009.

5. Brumitt J, Gilpin HE, Brunette M, and Meira EP. Incorporating ketlebells into a lower extremity sports rehabilitation program. North American Journal of Sports Physical Therapy: NAJSPT 5: 257, 2010.

6. Cohen J. Statistical Power Analysis for the Behavioral Sciences. 2nd edn. Hillsdale, New Jersey: L. Erlbaum, 1988.

7. Farrar RE, Mayhew JL, and Koch AJ. Oxygen cost of kettlebell swings. Journal of Strength \& Conditioning Research 24: 1034-1036, 2010.

8. Faul F, Erdfelder E, Lang A-G, and Buchner A. G* Power 3: A flexible statistical power analysis program for the social, behavioral, and biomedical sciences. Behavior research methods 39 : 175-191, 2007.

9. $\quad$ Fedorenko V. WKC Master Trainer Course Version 1.1. World Kettlebell Club, 2009.

10. Hermens HJ, Freriks B, Disselhorst-Klug C, and Rau G. Development of recommendations for SEMG sensors and sensor placement procedures. Journal of electromyography and Kinesiology 10: 361-374, 2000.

11. Hulsey CR, Soto DT, Koch AJ, and Mayhew JL. Comparison of kettlebell swings and treadmill running at equivalent rating of perceived exertion values. Journal of Strength \& Conditioning Research 26: 1203-1207, 2012.

12. Lake JP, Hetzler BS, and Lauder MA. Magnitude and relative distribution of kettlebell snatch force-time characteristics. The Journal of Strength \& Conditioning Research 28: 3063-3072, 2014.

13. Lake JP and Lauder MA. Kettlebell swing training improves maximal and explosive strength. Journal of Strength \& Conditioning Research 26: 2228-2233, 2012.

14. Lake JP and Lauder MA. Mechanical demands of kettlebell swing exercise. Journal of Strength \& Conditioning Research 26: 3209-3216, 2012.

15. Malinzak RA, Colby SM, Kirkendall DT, Yu B, and Garrett WE. A comparison of knee joint motion patterns between men and women in selected athletic tasks. Clinical Biomechanics 16: 438-445, 2001.

16. Matthews $M$ and Cohen D. The modified kettlebell swing. Strength \& Conditioning Journal 35: 79-81, 2013.

17. McAllister MJ, Hammond KG, Schilling BK, Ferreria LC, Reed JP, and Weiss LW. Muscle activation during various hamstring exercises. The Journal of Strength \& Conditioning Research 28: 1573-1580, 2014.

18. McGill SM and Marshall LW. Kettlebell swing, snatch, and bottoms-up carry: back and hip muscle activation, motion, and low back loads. Journal of Strength \& Conditioning Research 26: 16-27, 2012. 
19. Opar DA and Serpell BG. Is there a potential relationship between prior hamstring strain injury and increased risk for future anterior cruciate ligament injury? Archives of physical medicine and rehabilitation 95: 401-405, 2014.

20. Opar DA, Williams M, Timmins R, Hickey J, Duhig S, and Shield A. Eccentric hamstring strength and hamstring injury risk in Australian footballers. Medicine \& Science in Sports \& Exercise 47: 857-865, 2014.

21. Opar DA, Williams MD, Timmins RG, Dear NM, and Shield AJ. Knee flexor strength and bicep femoris electromyographical activity is lower in previously strained hamstrings. Journal of Electromyography and Kinesiology 23: 696-703, 2013.

22. Opar DA, Williams MD, Timmins RG, Dear NM, and Shield AJ. Rate of torque and electromyographic development during anticipated eccentric contraction is lower in previously strained hamstrings. The American journal of sports medicine 41: 116-125, 2013.

23. Orchard JW, Seward $\mathrm{H}$, and Orchard JJ. Results of 2 decades of injury surveillance and public release of data in the Australian Football League. The American journal of sports medicine: 0363546513476270, 2013.

24. Otto III WH, Coburn JW, Brown LE, and Spiering BA. Effects of weightlifting vs. kettlebell training on vertical jump, strength, and body composition. Journal of Strength \& Conditioning Research 26: 1199-1202, 2012.

25. Ross JA, Wilson CJ, Keogh JW, and Lorenzen C. External kinetics of the kettlebell snatch in amateur lifters. PeerJ 5:e3111;DOI 10.7717/ peerj.3111, 2017.

26. Ross JA, Wilson CJ, Keogh JW, Wai Ho K, Lorenzen C, Lake J, and Newton H. Snatch trajectory of elite level girevoy (Kettlebell) sport athletes and its implications to strength and conditioning coaching. International Journal of Sports Science and Coaching 10: 439-452, 2015.

27. Rudnev S. IKSFA Kettlebell sport coach manual. . IKSFA, 2010.

28. Serpell BG, Scarvell JM, Ball NB, and Smith PN. Mechanisms and risk factors for noncontact $A C L$ injury in age mature athletes who engage in field or court sports: a summary of the literature since 1980. The Journal of Strength \& Conditioning Research 26: 3160-3176, 2012.

29. Timmins RG, Opar DA, WIlliams MD, Schache AG, Dear NM, and Shield AJ. Reduced biceps femoris myoelectrical activity influences eccentric knee flexor weakness after repeat sprint running. Scandinavian journal of medicine \& science in sports 24: e299-e305, 2014.

30. Van Gelder LH, Hoogenboom BJ, Alonzo B, Briggs D, and Hatzel B. EMG Analysis and Sagittal Plane Kinematics of the Two-Handed and Single-Handed Kettlebell Swing: A Descriptive Study. International journal of sports physical therapy 10: 811, 2015.

31. Westing S, Cresswell A, and Thorstensson A. Muscle activation during maximal voluntary eccentric and concentric knee extension. European journal of applied physiology and occupational physiology 62: 104-108, 1991.

32. Yao W, Fuglevand RJ, and Enoka RM. Motor-unit synchronization increases EMG amplitude and decreases force steadiness of simulated contractions. Journal of Neurophysiology 83: 441-452, 2000.

33. Zebis M, Skotte J, Andersen C, Mortensen P, Petersen H, Viskær T, Jensen T, Bencke J, and Andersen L. Kettlebell swing targets semitendinosus and supine leg curl targets biceps femoris: an EMG study with rehabilitation implications. British journal of sports medicine 47: 1192-1198, 2013. 


\begin{tabular}{ccccc}
\hline Swing Type & Portion of & \%MH sEMG & \%BF sEMG & P \\
& ROM & $($ Mean \pm SD) & (Mean \pm SD) & \\
\hline Squat & Full repetition & $30.70 \pm 14.12$ & $21.69 \pm 9.18$ & $0.022^{*}$ \\
\hline Hip & Full repetition & $35.74 \pm 16.66$ & $24.50 \pm 9.19$ & $0.046^{*}$ \\
\hline $\begin{array}{c}\text { Double knee } \\
\text { extension }\end{array}$ & Full repetition & $29.58 \pm 16.88$ & $20.03 \pm 11.96$ & $0.007^{*}$ \\
\hline
\end{tabular}

Table 1. Comparison of the normalised surface electromyography (sEMG) during a full repetition for the medial hamstrings $(\mathrm{MH})$ and biceps femoris (BF) across each swing, ROM $=$ Range of Motion, $\mathrm{SD}=$ Standard Deviation, $95 \% \mathrm{CI}=95 \%$ Confidence Interval, $*=\mathrm{p}<0.05$ when comparing all medial vs biceps femoris $\mathrm{SEMG}$ at each individual swing. 


\begin{tabular}{cccc}
\hline Swing Type & Portion of ROM & $\begin{array}{c}\text { \%MH sEMG } \\
(\text { Mean } \pm \text { SD) }\end{array}$ & $\begin{array}{c}\text { \% BF sEMG } \\
\text { (Mean } \pm \text { SD) }\end{array}$ \\
\hline Squat & Concentric & $40.32 \pm 22.70$ & $26.47 \pm 7.91$ \\
& Eccentric & $23.49 \pm 13.58$ & $16.93 \pm 9.93$ \\
\hline Hip Hinge & Concentric & $44.89 \pm 25.02$ & $32.65 \pm 14.47$ \\
& Eccentric & $28.80 \pm 16.36$ & $21.51 \pm 15.04$ \\
\hline $\begin{array}{c}\text { Double knee } \\
\text { extension }\end{array}$ & Concentric & $34.25 \pm 20.70$ & $25.72 \pm 15.79$ \\
& Eccentric & $20.87 \pm 9.99$ & $14.89 \pm 6.98$
\end{tabular}

Table 2. Comparison of the normalised surface electromyography (sEMG) for the medial hamstrings $(\mathrm{MH})$ and biceps femoris $(\mathrm{BF})$ within the concentric and eccentric muscle action. $\mathrm{ROM}=$ Range of Motion, $\mathrm{SD}=$ Standard Deviation 